\title{
Reconceptualizing Causative Factors and Intervention Strategies in the Eating Disorders: A Shift From Body Image to Self-Concept Impairments
}

\author{
Karen Farchaus Stein* and Colleen Corte ${ }^{\dagger}$
}

\begin{abstract}
In this report, we argue that impairments in self-concept development function as a cognitive vulnerability that contributes to the formation of the eating disorders (ED) of anorexia nervosa (AN) and bulimia nervosa (BN). More specifically we argue that impairments in development of the total collection of identities that comprise the self-concept contribute to body image disturbances which in turn, motivate the eating and body-weight attitudes and behaviors that characterize the disorders. First, we review current understandings of the role of body image disturbances in the ED and discuss limitations of this approach. Then we review theories from psychoanalytic and feminist traditions that suggest that identity disturbances are a key factor in the etiology of the ED. Next, results of studies that examine identity disturbances in the ED are reviewed. Results of a study of women with AN and BN using the schema model of the selfconcept as the theoretical framework showed that women with few positive and many negative self-cognitions are particularly vulnerable to cultural messages about body weight and form weight-related cognitions about the self that contribute to disordered eating attitudes and behaviors. Finally, the implications of these findings for primary and secondary level prevention of ED are addressed.
\end{abstract}

(C) 2003 Elsevier Inc. All rights reserved.

$\mathbf{T}$ HE EATING DISORDERS of anorexia nervosa (AN) and bulimia nervosa $(\mathrm{BN})$ are serious health problems that affect as many as 5 million American adolescent and young adult women each year and cause life-threatening physical complications and compromised states of emotional and social well-being. AN is a clinical syndrome characterized by three distinct types of symptoms: (1) disordered attitudes toward body weight including intense fear of becoming fat and undue influence of weight on self-evaluation, (2) failure to maintain body weight at least at $85 \%$ of ideal, and (3) amenorrhea for at least 3 consecutive months (American Psychiatric Association, 2000). In contrast to the $\mathrm{AN}$ diagnostic criteria that focus on attitudes and biological outcomes of disordered eating behaviors, criteria for the $\mathrm{BN}$ diagnosis are attitudinal and behavioral and include three distinct types of symptoms: (1) bingeing or ingesting objectively large quantities of food within a 2 hour period of time while feeling out of control, (2) purging (e.g., self-induced vomiting, laxative or diuretic use) or nonpurging (fasting or excessive exercise) compensatory weight control behaviors in response to the binge with the cycle occurring at

From the *University of Michigan School of Nursing and the University of Michigan Addiction Research Center, Ann Arbor, MI.

Supported by the National Institute for Nursing Research grant nos. R29NR02457 and R01RN05277.

Address reprint requests to Karen Farchaus Stein, $\mathrm{PhD}$, The University of Michigan School of Nursing, 400 N. Ingalls, Room 2160, Ann Arbor, MI 48109. E-mail: kfarchau@umich.edu

(c) 2003 Elsevier Inc. All rights reserved.

0883-9417/03/1702-0002\$30.00/0

doi:10.1053/apnu.2003.50000 
least twice weekly for a period of at least 3 months, and (3) disordered attitudes including undue influence of body weight on self-esteem. Although AN and $\mathrm{BN}$ are conceptualized as discrete categories, in clinical practice considerable overlap in symptoms and movement back and forth across the disorders and their subthreshold variants are observed (American Psychiatric Association, 2000; Walsh \& Garner, 1997). Furthermore, while many important differences between the two disorders have been identified (Russell, 1997) theories of cause of the two disorders often converge (Stein, 1996; Strober, Freeman, Lampert, Diamond \& Kaye, 2000).

A major focus in eating disorder research has been on the identification of cultural, familial, and individual factors that contribute to the formation and progression of the disorders, and therefore, can be targeted for primary prevention, and to promote recovery and cure. One aspect of the individual that has been consistently viewed as an important determinant of the eating disorder (ED) is the self-concept. Dating from early psychodynamic theories to the more contemporary cognitive approaches, the ED have been characterized as stemming from disturbances of the self (Bruch, 1982; Straumann, Vookel, Bernestein, Chaiken, \& Higgins, 1991; Vitousek, \& Ewald, 1993).

In this report we build on the view that $\mathrm{AN}$ and $\mathrm{BN}$ stem from disturbances in the self and argue that impairments in self-concept development function as a cognitive vulnerability that contributes to the formation of eating disorder symptoms. The majority of research on the role of the self in ED has focused on one dimension of the selfconcept, body image. These studies have shown that women with $\mathrm{AN}$ and $\mathrm{BN}$ are more likely to define themselves as fat and are dissatisfied with their body weight (Cash \& Deagle, 1997). Furthermore, these weight-related cognitions and attitudes are predictive of eating and weight control behaviors that characterize the disorders. Studies have shown important links between cultural norms regarding female body weight and body dissatisfaction and overestimation of body size (Stice \& Shaw, 1994). Yet despite their important contribution toward understanding the proximal cause of disordered eating behaviors, these studies have left the question of why some women are vulnerable to cultural norms regarding body weight unaddressed. In this article we review theoretical and empirical work that suggests that basic disturbances in selfconcept development motivate a search for a meaningful identity and a focus on body image as a source of esteem and respect. More specifically, we focus on characteristics of the set of identities that are available in memory and argue that women with few positive and many negative identities are particularly vulnerable to cultural messages about body weight, and as a result, form weight-related self-cognitions that contribute to disordered eating symptoms.

To build our argument that the ED stem from disturbances in self-concept development, we begin with a review of current understandings of the role of body image disturbances in the ED and address limitations of this approach. Next we review theories from psychoanalytic and feminist orientations that suggest that impairments in overall self-concept development are an important factor in the formation of the ED. Although these theories offer important insights into the role of self-concept impairments in the ED and factors that contribute to the development of the selfconcept impairments, the theories do not adequately define the self-related constructs. Terms such as self, sense of self, identity and self-concept are used interchangeably and theoretical and operational definitions are not provided. Consequently, the specific construct being addressed remains vague and the mechanisms to link the self-concept disturbance to the eating disorder symptoms are unclear (Stein \& Nyquist, 2001). To address these problems, we introduce a contemporary model of the self-concept, the schema model, and link this model to the self-concept disturbances outlined in the psychodynamic and feminist theories. Next we report the results of a study based on the schema model that investigates the hypothesized relations between self-concept impairments, body image disturbances and ED. Finally, we address the nursing care implications of this approach.

\section{BODY IMAGE DISTURBANCES AND THE EATING DISORDERS}

Disturbances in body image are a defining feature of $\mathrm{AN}$ and $\mathrm{BN}$ and an important cause of disordered eating behaviors. Hilde Bruch, an early psychodynamic eating disorder theorist, argued that the misperception of the self as fat and the absence of concern regarding the objective emaciation are essential defining symptoms of $\mathrm{AN}$ 
(Bruch, 1981). The idea that body image disturbances are a defining property has since been extended to BN (Cooper \& Taylor, 1988), and in fact, it is included as a requisite symptom for both disorders in the Diagnostic and Statistical Manual for Mental Disorders 4th Edition (American Psychiatric Association, 1994).

Empirical efforts to examine body image disturbances in the ED have focused on two distinct dimensions, perceptual body-size distortion and evaluative dissatisfaction (Cash \& Deagle, 1997). Perceptual body-size distortion is defined as the inability to accurately estimate one's body size (Cash \& Deagle, 1997) and has been measured using a variety of nonword-based body-size estimation techniques such as the moveable caliper technique and the distorted photograph technique (Cash \& Brown, 1987 for a review). The discrepancy between the subjective estimate and objective measurement of body size is used as an indicator of perceptual deficits. Although findings suggest that individuals with $\mathrm{AN}$ and $\mathrm{BN}$ overestimate body size, (Horne, Van Vactor, \& Emerson, 1991; Smeets, Smit, Panhuysen \& Ingleby, 1998), an important limitation of this research is that the specific construct being measured by the techniques is not clearly understood (Smeets, 1997; Stein, 1996). Although many investigators argue that the body size overestimation is an indicator of underlying perceptual processing abnormalities that interfere with one's ability to accurately perceive body size, the fact that participants are asked to estimate their body size without seeing an image of the self either in a mirror or photograph indicates that perceptual processes are not involved in the task. Rather the body size estimation techniques require that participants activate or even construct a memory of the physical self to use as the basis of their judgement (Smeets, 1997). This suggests that rather than a perceptual problem, the person's cognitive representations of the physical self are inaccurate, reflect old states of the physical self, or perhaps are cognitive products based on comparisons to unrealistic standards.

The second dimension of body image disturbance that has been examined is body dissatisfaction. Body dissatisfaction is an enduring memory structure that reflects a negative evaluation of the physical self (Eagly \& Chaiken, 1998). A metaanalysis of 66 studies completed by Cash and Deagle (1997) showed that women with AN and
BN are significantly more dissatisfied with their body size and shape compared to control women, and the effect size was large. They highlight the significance of this finding given that recent studies have shown that a majority of American women hold negative attitudes toward their physical self (Rodin, Silberstein \& Striegle-Moore, 1986). Furthermore, high levels of body dissatisfaction are predictive of feelings of fatness, dieting and bingeing behaviors (Stice, Mazotti, Krebs, \& Martin, 1998) and negative affect states (Cooper \& Taylor, 1988).

Recently eating disorder research has shifted focus to factors that contribute to body image disturbances in adolescent and young adult women. A growing collection of studies has shown that changing cultural norms shifting toward thinner female body ideal and media messages that highlight extreme thinness increase body dissatisfaction in normal samples of high school and college-aged women (Harrison \& Cantor, 1997; Stice \& Shaw, 1994). However, one important question that has received less attention is, what are the characteristics of women who are most vulnerable to cultural messages regarding ideal body weight and most likely to internalize those unrealistic images as standard to evaluate the self? Given that messages about ideal female body weight are pervasive in our culture, yet only approximately $10 \%$ of the adolescent and young adult population develops eating disorder symptoms, important individual differences must mediate their effects.

\section{SELF-CONCEPT DISTURBANCES AND THE EATING DISORDERS: THEORETICAL AND EMPIRICAL PERSPECTIVES}

\section{Psychodynamic Theories}

As mentioned earlier, Bruch identified disturbances in body image as the proximal cause of the eating disorder, particularly AN, and it is this component of her theory that has received the most attention. However, a second and equally important tenet of Bruch's theory was that disturbances in overall identity development are the cornerstone of the disorder (Furumoto \& Keating, 1995). She argued that at its core, anorexia nervosa is "a struggle for control, for a sense of identity, competence and effectiveness" (Bruch, 1973, p. 251). Highly controlling and perfectionistic parenting was posited to limit opportunities for autonomous 
functioning and interfere with the development of a clear and elaborated sense of one's self. As the child without an emerging identity encounters the biological and social challenges associated with adolescence, this lack of autonomous self-definition gives rise to feelings of incompetence, selfdoubt and fear of losing control. To compensate for the lack of a clear identity and the associated feelings of ineffectiveness and powerlessness, Bruch (1981) argued that the adolescent turns to body weight, a highly salient and culturally-valued domain, as a viable source of self-definition.

Since Bruch's original theoretical speculations, other psychodynamic theorists have similarly suggested that the failure to develop a diverse and stable set of identities is fundamental to the formation of the ED. Goodsitt (1997) argues that disturbances in parent-child relationship caused by stressors, mental disorder or other illness, disrupt the process of self-concept development and results in a vague, disorganized sense of self that lacks stability and coherence. The behaviors that characterize AN and BN are posited to restore a sense of cohesion, increase feelings of effectiveness and serve as a "compensatory identity or selfhood that allows some contrived sense of having a significant and meaningful presence in the world" (Goodsitt, 1997, p. 210). Sands (1991) suggests that parenting problems related to identification and appropriate responding to child's affects and needs disrupts the parent-child relationship essential for the formation of the self-concept. Strober (1991) posits that a genetically based personality style of high stimulus-avoidance, low novelty seeking, and high reward dependence, rather than restrictive parental behaviors alone, inhibits exploratory activities necessary for normal self-concept development. Most recently, Bulik and Kendler (2000) addressed the idea that an eating disorder identity functions as the solution to a poorly defined self and argued that the process of recovery requires giving up the central self-defining identity of "eating disordered." Furthermore, they suggest that taking away the eating disorder identity without the creation of other viable and meaningful identities "can leave a frightening void" (p. 1759).

\section{Feminist Theories}

The hypothesis that $\mathrm{AN}$ and $\mathrm{BN}$ stem from impairments in identity development is also central to feminist theories of the ED. Although many of the feminist formulations of the ED begin with the idea that the extreme focus on body image is a desperate attempt to cope with the lack of a stable and authentic sense of self, and cite Bruch's work as the foundation of their theories, they modify and extend the work by focusing on unique factors in the development of the female self and highlight contextual factors that impede this process.

Innate and developmental differences in interpersonal relatedness between females and males are believed to contribute to differences in ability to recognize and discern subjective experiences and delineate the authentic self (deGroot \& Rodin, 1994; 1998). Feminist psychoanalytic theorists have argued that psychosocial development of girls is marked by the ongoing identification and relatedness to the mother or caregiver (Chodorow, 1978). Although the development of boys is marked by the recognition of the differences between the self and the caregiver, for girls, identification with mothering figure persists and boundaries or distinctions between the self and other are less clear. A consequence of this normal developmental pathway in girls is that the self-concept may, to a great extent, reflect internalized traits, values, and ideals stemming from the identifications such that prevailing cultural standards regarding women, femininity and body weight may become an integral component of the self (SteinerAdair, 1990).

Innate differences in capacity for empathy may also contribute to a greater sensitivity to the reactions of others in females and result in a greater reliance on external sources to evaluate and define the self. deGroot \& Rodin (1994) summarize research findings suggesting that from early infancy, girls are more sensitive and reactive to the emotional responses of others. Although this capacity for empathic connection may serve to strengthen interpersonal relatedness, it may also lead to an increased reliance on reactions of others to define the self. Because circumstances in the interpersonal environment are constantly changing, this high reliance on others for feedback may interfere with development of the ability to focus on subjective reactions, desires, and needs, and consequently may interfere with the articulation of an internally grounded sense of oneself.

A number of feminist theorists directly link the ED to cultural pressures and conflicts that interfere with the development of a rich and satisfying set of 
identities and necessitate reliance on the "feminine ideal" as a way to cope with the absence of an authentic self (Malson, 1999; Piran, 2001). Boskind-Lodahl (1976) argues that the social context rewards physical attractiveness and submissiveness, and sanctions self-reliance, independence and assertiveness, and in doing so these cultural values become the personal goals motivating behavior and the standards for defining and evaluating the self. Achieving the collective vision of the ideal woman, thin, pretty, and good becomes the means for achieving desired rewards such as interpersonal closeness (i.e., wifehood and motherhood), financial and personal success.

\section{Empirical Perspectives}

When taken together, the psychoanalytic and feminist theories converge to highlight the centrality of impairments in the total self-concept in the cause of ED. Yet empirical support for this perspective has been limited. The few studies that have focused on the overall self-concept suggest that impairments in the total self-concept contribute to the formation and persistence of both AN and BN. Schupak-Neuberg and Nemeroff (1993) found that women with BN have greater self-concept impairments including higher levels of identity confusion, a greater sense of enmeshment with others, and less stable self-definitions over time than binge eating women who do not engage in compensatory behaviors and controls. Paxton and Sculthorpe (1991) suggest that the disorders may more likely stem from the relative absence of positive conceptions of the self and the internalization of the negative aspects of the female stereotype. They found that college women who described themselves as possessing fewer positive and more negative feminine traits, and more negative traits in general, reported higher levels of disordered eating behaviors.

A study completed by Stein and colleagues provides further support for the hypothesis that selfconcept impairments are an important determinant of the ED. This study addresses an important problem that has interfered with the empirical testing of the identity impairment and ED hypothesis-the lack of clear and measurable definitions of selfrelated constructs (Stein \& Nyquist, 2001). Because ED studies completed to date have not been based on a theoretical model of the self-concept, it is difficult to understand the exact meaning of terms such as "self," "self-concept," sense of self," and "identity," which are widely used in the ED literature. Another important consequence is that the specific nature of the self-concept disturbance underlying the ED remains unclear. This is important because without knowledge of how the self is linked to disordered eating attitudes and behaviors, no clear focus for intervention exists. In our study, a contemporary cognitive model of the self-concept called the schema model (Markus, 1977) is used as the theoretical framework to investigate the role of the self in women with anorexia and bulimia nervosa.

According to the schema model, the self-concept is a complex memory structure that is comprised of specialized units of knowledge about the self in specific content areas that are referred to as selfschemas. A self-schema is itself an elaborate knowledge structure about the self that is formed in an area of particular interest and meaning for the individual. Self-schemas can be formed around a variety of different aspects of the self including social roles, skills, talents or interests, demographic characteristics, and personality traits.

Once formed, self-schemas play an important role in processing information and regulating affect and behavior. Persons with a self-schema in a content area will selectively attend to stimuli relevant to that domain, process relevant stimuli more quickly, with more certainty and will be more likely to encode the stimulus in memory making it accessible for future recall (Markus, Hammill, \& Sentis, 1987). The specific function of self-schemas in regulating affect and behavior, however, depends on their valence (positivity or negativity). Positive self-schemas serve as important motivators of behavior and are associated with more reliable behavioral performance in the domain (Kendzierski, 1988; Cross \& Markus, 1994), and positive affect (Herzog, Franks, Markus, \& Homberg, 1998; Thoits, 1986). In contrast, negative self-schemas inhibit behavior in the domain and are associated with negative affect states (Andersen \& Cryanowski, 1994; Cyranowski \& Andersen, 1998). Therefore, positive self-schemas may be viewed as cognitive resources that facilitate effective behavioral functioning whereas negative self-schemas may be viewed as cognitive liabilities that inhibit behavior.

The self-concept from this theoretical perspective refers to the individual's total collection of 
valenced self-schemas and other less fully developed conceptions of the self. Because of the differential function of positive and negative selfschemas, theorists have suggested that the relative absence of positive self-schemas (Campbell \& Lavallee, 1993; Kernis, Paradise, Whitaker, Wheatman, \& Goldman, 2000) and the presence of many negative self-schemas (Malle \& Horowitz, 1995) contributes to a vague, uncertain or impoverished sense of self that may in turn motivate a search for an alternative definition of the self.

Linking this theoretical perspective to the psychodynamic and feminist models that suggest that the ED stem from having few stable, authentic and meaningful identities, and the work of Paxton and Schulthorpe that highlighted the importance of negative identities, as well as what is known about the functional role of positive and negative selfschemas, Stein's study (Stein \& Nyquist, 1998) tested the hypotheses that women with an eating disorder would have fewer positive and more negative self-schemas available in memory. Furthermore, it was hypothesized that this constellation of self-schemas would predict the presence of a fat body-weight self-schema that would in turn predict body dissatisfaction and disordered eating behaviors. Participants included 79 women with a clinically diagnosed ED of AN or BN and 32 healthy controls. Of the 79 women with an eating disorder, 26 met either full $(\mathrm{n}=12)$ or subthreshold $(\mathrm{n}=$ 14) diagnostic criteria for AN. Fifty-three women met either full $(n=29)$ or subthreshold $(n=24)$ diagnostic criteria for $\mathrm{BN}$.

The number of valenced self-schemas was measured using an open-ended card-sort task (Zajonc, 1960) combined with Markus' (1977) methodology to identify self-schemas. The availability of a fat self-schema was determined using a computerized self-descriptive adjective endorsement rating task and two information processing indicators. Body dissatisfaction (Eating Disorders Inventory [EDI], Garner, 1991) and eating disorder behaviors (Johnson, 1985) were also measured.

Results support the hypothesis that women with $\mathrm{AN}$ and BN have an impaired self-concept which serves as a cognitive vulnerability to disordered eating attitudes and behaviors. Women in the AN and $\mathrm{BN}$ groups had fewer positive and more negative self-schemas than controls (positive: 10.69 vs 9.78 vs $15.00, t \mathrm{~s} \geq 2.18, p \mathrm{~s} \leq .04$; negative: 5.42 vs 4.63 vs $1.34, t \mathrm{~s} \leq-4.84, p \mathrm{~s}<.001)$. Women with BN also showed a pattern of adjective endorsements and information processing evidence of a fat self-schema, and because the majority were of normal weight, this suggests that women with $\mathrm{BN}$ have an unrealistic conception of the self as fat. Contrary to predictions, however, women with AN did not show evidence of a fat self-schema. Finally, the number of positive self-schemas (Beta $=$ -.38) negatively predicted the fat self-schema, whereas the number of negative self-schemas $($ Beta $=.19)$ and body mass index $($ Beta $=.37)$ positively predicted the fat self-schema, which in turn predicted $36 \%$ of the variance in body dissatisfaction. The same model also accounted for $17 \%$ of the variance in eating disorder behaviors. The second model also included a path showing body mass index (Beta $=-.25$ ) directly negatively predicting eating disorder behavior, probably reflecting women with AN.

Taken together, these findings provide empirical support for the fact that women with $\mathrm{AN}$ and $\mathrm{BN}$ have an impaired self-concept, i.e., fewer positive and more negative self-schemas available in memory. Although women with BN showed clear evidence of a fat self-schema whereas women with AN did not, predictive models showed that for all women, a self-concept that is comprised of few positive and many negative self-schemas contributes to the formation of a fat self-schema, which in turn leads to body dissatisfaction and disordered eating.

\section{NURSING CARE IMPLICATIONS OF THE SELF-CONCEPT IMPAIRMENT APPROACH TO THE EATING DISORDERS}

Research findings reported above are consistent with the theoretical position that impairments in the self-concept including the presence of relatively few positive and many negative self-schemas render the individual vulnerable to cultural pressures regarding body weight and are at increased risk of focusing on body weight as a key source of self-definition. The body-weight selfschema, in turn, is predictive of the disordered attitudes and behaviors that characterize AN and BN. This shift in emphasis to disturbances in the development of the total collection of self-schemas or identities as a primary cause of the ED has important implications for the primary and secondary levels of nursing care of women across their lifespan. Rather than focusing primarily on body 
image and the social and cultural pressures that shape body image, this empirically supported theoretical approach suggests interventions should target the development of a diverse collection of self-schemas. It is important to note, however, that while the proposed interventions are derived from the model of self-concept disturbances as a primary source of the eating disorders, empirical testing is required before their efficacy in the prevention and the promotion of recovery from the eating disorders can be confidently argued.

\section{Implications for Primary Prevention}

Psychoanalytic theories focus attention on the importance of parent-child interactions in the development of the self. According to this view, earliest core conceptions of the self form around the recognition of subjective internal states such as emotions, biological needs (i.e., hunger, satiety) and drives for exploration and separation. Parental interactions that accurately and appropriately acknowledge the infant's internal states are essential to the early foundations of a healthy self. Based on this view, health focused parenting interventions that aim to improve the quality of interaction between the parent and child and support the development of the earliest rudiments of the self-concept may be viewed as primary prevention of ED. Starting in early infancy, interventions to teach parents how to identify and appropriately respond to infant and child needs will play an important role in the development of a healthy self and serve to decrease the risk of ED later in life.

As the infant moves into toddler and preschool levels, interventions to support parents around the child's needs for separation, exploration and healthy connection will further contribute to the development of a healthy self (Mahler \& McDevitt, 1989). Although while Strober (1991) has suggested that a genetically based shy/fearful personality style may inhibit exploration essential to the development of a healthy self, researchers have shown that individual differences in parenting style can modulate this personality style, decrease the associated fearfulness and anxiety, and increase capacity for confident environmental exploration (Kagan, 1979). Interventions designed to foster a more relaxed, confident parenting style may be effective in decreasing the child's level of anxiety and facilitate exploration essential to the development of the self.
Feminist theories of ED draw attention to the influences of the broader cultural context on development of the self-concept. Limited opportunities, conflicting messages about the desirability of competitiveness, competence, and aggression in girls, and ideals that highlight unrealistic visions of beauty interfere with the development of a rich collection of personally meaningful identities. Primary prevention interventions based on the feminist perspective might focus on proximal contacts such as the family, school or athletic team and would strive to insulate and protect the child in ways that would foster healthy self-concept development. For example, interventions designed to teach parents about the cultural messages about weight and the negative effects on female development may help parents reflect on their own values and expectations for their children. Interventions may also focus on increasing opportunities for participation in nontraditional types of activities that foster exploration and skill development and contribute to the development of a rich and diverse set of identities. Interventions might also focus on changing cultural norms and messages that impede self-concept development in females (Austin, 2000). Efforts to change policy and laws related to the opportunities for women and diet and advertising industries may reduce or limit the negative effects of the broader social environment on the development of the self.

\section{Implications for Secondary Prevention}

Secondary preventions are most often focused on the individual rather than the social context. Again, psychoanalytic and feminist approaches to intervention for ED focus on discovery and elaboration of the authentic self. The goal of therapy is to help women become aware of and responsive to impulses, feeling, desires, needs, and goals that originate within themselves (Bruch, 1980) and "to gain self-confidence and become more competent in living as self-directed individuals" (Bruch, 1979, p. 260). Decades ago, Bruch (1962) argued that key strategies for effective psychotherapy were to fact find, question and listen carefully, and empathically support new expressions of the self. Since that time, other psychoanalytic theorists have similarly emphasized the importance of helping women with AN and BN to identify previously unrecognized aspects of the self and to validate and support the elaboration and development of emerg- 
ing self-definitions (see Rizzuto, Peterson \& Reed, 1981; Sands, 1991).

In our own work, we are currently conducting a randomized clinical trial of a new form of psychotherapy that builds on our research findings that a self-concept comprised of few positive and many negative self-schemas contributes to the formation of a body weight self-schema and the eating and weight-control attitudes and behaviors that characterize the ED. The aim of the psychotherapy, referred to as the Identity Intervention Program (IIP), is to facilitate the development of new positive self-schemas as the means to decrease symptoms and improve health in women with ED. It is predicted that interventions to systematically increase the number of positive self-schemas in non-weight related domains will contribute to a clearer and more stable sense of self, a more developed framework for processing self-relevant stimuli, and a larger and more diverse set of interests, commitments, plans and strategies to motivate goal-directed behavior. Consequently, body weight will no longer serve as the primary source of selfdefinition and ED symptoms will be reduced. Because interventions are not likely to be effective in eliminating existing self-schemas (Mahoney, 1985) and may paradoxically increase their activation in working memory, the IIP does not focus on altering existing body weight or negative self-schemas.

The IIP includes behavioral, cognitive and social interventions to facilitate the development of new positive self-schemas. The 20 -week program includes weekly individual psychotherapy and concurrent weekly group psychotherapy. Cognitive strategies such as imagining the self in the new role or identity, role-playing, and the use of activities such as the construction of collages are used to foster development of the memory structure about the self in the content area (i.e., the self-schema). Based on studies that have shown that behavioral participation plays an essential role in the development of self-schemas (Klein, Sherman \& Loftus, 1996), interventions are designed to help the individual initiate and sustain behavioral participation in a self-selected content area. Barriers to active participation in the content area are identified and addressed. Social interventions in the form of group psychotherapy are used to provide external support and reinforcement for the target behaviors and developing self-schemas. Finally, in keeping with the American Psychiatric Association, Practice Guidelines for the Treatment of Patients with Eating Disorders (2000), concurrent nutritional counseling is provided to restore weight and normalize eating behaviors, and medical care is provided to ensure that related physical health concerns are addressed.

Unlike the prevailing psychotherapies for AN and $\mathrm{BN}$, the IIP does not focus on eating patterns, weight control behaviors and body weight selfconceptions. Given evidence that suggests that self-schemas influence consistent and competent behavior in the domain, and the findings that the fat self-schema mediates the relationship between the positive and negative schemas and ED attitudes and behaviors, interventions that increase activation in working memory of the fat schema are likely to have the paradoxical effect of increasing ED behaviors and further elaborating this dysfunctional cognitive structure. Although our research is in the early stages and insufficient data are available to test the research hypothesis, the work holds promise for contributing a theoretically grounded nursing intervention that focuses on the total selfconcept as a means to promote recovery and increase health in women with an eating disorder.

\section{CONCLUSION}

The eating disorders of anorexia and bulimia nervosa are life-threatening mental disorders that affect millions of adolescent and young adult women each year. Psychoanalytic and feminist theories supported with recent empirical work suggest that impairments in overall identity development contribute to the formation and persistence of the attitudinal and behavioral symptoms that characterize the disorders. Nurses are well positioned to assume a leadership role in the prevention and treatment of the eating disorders. Primary prevention interventions designed to foster empathic parenting that is responsive to the unique needs, desires, and abilities of the child may contribute to healthy development of the self-concept and contribute to the prevention of eating disorders. Secondary prevention interventions that are focused on the identification and elaboration of authentic identities may similarly contribute to the reduction of eating disorder symptoms and the restoration of health. Currently we are conducting a randomized clinical trial of an IIP designed to ameliorate symptoms of the ED and promote health and well being 
through the development of new positive self-schemas. Additional research that focuses on the psychoanalytic and feminist proposition that links self-concept disturbances to eating disorder symptoms may be key to the prevention and the promotion of a full and enduring recovery from these debilitating disorders.

\section{ACKNOWLEDGMENT}

The authors acknowledge the contributions of Linda Nyquist, $\mathrm{PhD}$ and research assistance of Kristen Hedger, Jennifer Sandoz, Judy Sargent, and Elizabeth Brough in the completion of the initial eating disorder study.

\section{REFERENCES}

American Psychiatric Association. (1994). Diagnostic and statistical manual of mental disorders (4th Ed.). Washington, DC: Author.

American Psychiatric Association. (2000). Practice guidelines for the treatment of patients with eating disorders (Revision). American Journal of Psychiatry, 157, 1-39.

Andersen, B., \& Cyranowski, J. (1994). Women's sexual selfschemas. Journal of Personality and Social Psychology, 67(6), 1079-1100.

Austin, S.B. (2000). Prevention research and the eating disorders: Theory and new directions. Psychological Medicine, 30, 1249-1262.

Boskind-Lodahl, M. (1976). Cinderella's stepsisters: A feminist perspective on anorexia nervosa and bulimia. Journal of Women in Culture and Society, 2, 342-356.

Bruch, H. (1962). Perceptual and conceptual disturbances in anorexia nervosa. Psychosomatic Medicine, 24, 187194.

Bruch, H. (1973). Eating disorders: Obesity, anorexia nervosa and the person within. New York: Basic Books.

Bruch, H. (1979). Developmental deviations in anorexia nervosa. Israel Annals of Psychiatry and Related Disciplines, 17, 255-261.

Bruch, H. (1980). Preconditions for the development of anorexia nervosa. The American Journal of Psychoanalysis, 40, 169-172.

Bruch, H. (1981). Developmental considerations of anorexia nervosa and obesity. Canadian Journal of Psychiatry, 26, 212-217.

Bruch, H. (1982). Anorexia nervosa: Therapy and theory. American Journal of Psychiatry, 139, 1531-1538.

Bulik, C., \& Kendler, K. (2000). "I am what I (don't) eat" Establishing an identity independent of an eating disorder. American Journal of Psychiatry, 157, 1755-1760.

Campbell, J.D., \& Lavallee, L.F. (1993). Who am I? The role of self-concept confusion in understanding the behavior of people with low self-esteem. In R.F. Baumeister (Ed.) The puzzle of low self-regard (pp. 3-20). New York, NY: Plenum Press.

Cash, T.F., \& Brown, T. (1987). Body image in anorexia nervosa and bulimia nervosa: A review of the literature. Behavior Modification: Special Issue: Behavioral and cognitive-behavioral treatment of anorexia nervosa and bulimia nervosa, 11, 487-521.

Cash, T.F., \& Deagle, E.A. (1997). The nature and extent of body image disturbance in anorexia nervosa and bulimia nervosa: A meta-analysis. International Journal of Eating Disorders, 22, 107-125.

Chodorow, N. (1978). The reproduction of mothering. Berkley: University of California Press.

Cooper, P., \& Taylor, M. (1988). Body image disturbance in bulimia nervosa. British Journal of Psychiatry, 153, 32-36.

Cross, S., \& Markus, M. (1994). Self-schemas, possible selves, and competent performance. Journal of Educational Psychology, 86, 423-438.

Cyranowski, J., \& Andersen, B. (1998). Schemas, sexuality, and romantic attachment. Journal of Personality and Social Psychology, 74, 1364-1379.

deGroot, J., \& Rodin, G. (1994). Eating disorders, female psychology and the self. Journal of the American Academy of Psychoanalysis, 22, 299-317.

deGroot, J., \& Rodin, G. (1998). Coming alive: The psychotherapeutic treatment of patients with eating disorders. Canadian Journal of Psychiatry, 43, 359-366.

Eagly, A., \& Chaiken, S. (1998). Attitude structure and function. In Gilbert, Fiske, S., \& Lindzey, G. (Eds.), Handbook of social psychology (4th Ed.) (pp. 269-322). Boston, MA: McGraw Hill.

Furumoto, L., \& Keating, K. (1995). Construing anorexia nervosa (1940-1980): The psychoanalysts, the behaviorists, and Hilde Bruch. In I. Lubek (Ed), Trends and issues in theoretical psychology (pp. 105-111). New York: Springer Publishing.

Garner, D. (1991). Eating Disorders Inventory-2 Professional Manual. Odessa, FL: Psychological Assessment Resources.

Goodsitt, A. (1997). Eating disorders: A self-psychological perspective. In D. Garner \& P. Garfinkel (Eds), Handbook of treatment for eating disorders (2nd Ed.) (pp. 205-228). New York: Guilford Press.

Harrison, K., \& Cantor, J. (1997). The relationship between media consumption and eating disorders. Journal of Communication, 47, 40-67.

Herzog, A.R., Franks, M.M., Markus, H.R., \& Holmberg, D. (1998). Activities and well-being in older age: effects of self-concept and educational attainment. Psychology and Aging, 13, 179-185.

Horne, R.L., Van Vactor, J., \& Emerson, S. (1991). Disturbed body image in patients with eating disorders. American Journal of Psychiatry, 148, 211-215.

Johnson, C.L. (1985). Initial consultation for patients with bulimia and anorexia nervosa. In D.M. Garner \& P.E. Garfinkel (Eds.), Handbook of psychotherapy for anorexia and bulimia (pp. 19-51). New York, NY: Guilford Press.

Kagan, J. (1979). The form of early development. Archives of General Psychiatry, 36, 1047-1054.

Kendzierski, D. (1988). Self-schemata and exercise. Basic and Applied Social Psychology, 9, 45-59.

Kernis, M.H., Paradise, A.W., Whitaker, D.J., Wheatman, S.R., \& Goldman, B.N. (2000). Master of one's psychological domain? Not likely if one's self-esteem is unstable. 
Personality and Social Psychology Bulletin, 26, 12971305.

Klein, S., Sherman, J., \& Loftus, J. (1996). The role of episodic and semantic memory in the development of trait selfknowledge. Social Cognition, 14, 277-291.

Mahler, M. \& McDevitt, J. (1989). The course of life, Vol 2: Early childhood. Madison, CT: International Universities Press.

Mahoney, M. (1985). Human change process: Notes on the facilitation of personal development. New York: Basic Books.

Malle, B.F., \& Horowitz, L.M. (1995). The puzzle of negative self-views: An explanation using the schema concept. Journal of Personality and Social Psychology, 68, 470484.

Malson, H. (1999). Women under erasure: Anorexic bodies in postmodern context. Journal of Community \& Applied Social Psychology, 9, 137-153.

Markus, H. (1977). Self-schemata and processing of information about the self. Journal of Personality and Social Psychology, 35, 63-78.

Markus, H., Hamill, R., \& Sentis, K. (1987). Thinking fat: Self-schemas for body weight and other processing of weight relevant information. Journal of Applied Social Psychology, 17, 50-71.

Paxton, S., \& Sculthorpe, A. (1991). Disordered eating and sex role characteristics in young women: Implications for sociocultural theories of disturbed eating. Sex Roles, 24, 587-598.

Piran, N. (2001). Reinhabiting the body. Feminism \& Psychology, 11, 172-176.

Rizzuto, A., Peterson, R., \& Reed, M. (1981). The pathological sense of self in anorexia nervosa. Psychiatric Clinics of North America, 4, 471-487.

Rodin, J., Silberstein, L., Striegel-Moore, R. (1984). Women and weight: A normative discontent. In T.B. Sonderegger (Ed.), Nebraska Symposium of Motivation: Vol. 32. Psychology and gender (pp.267-307). Lincoln: University of Nebraska Press.

Russell, G. (1997). The history of bulimia nervosa. In D. Garner \& P. Garfinkel (Eds), Handbook of treatment for eating disorders (2nd Ed.) (pp. 11-24). New York: Guilford Press.

Sands, S. (1991). Bulimia, dissociation, and empathy: A selfpsychological view. In C. Johnson (Ed.), Psychodynamic treatment of anorexia nervosa and bulimia nervosa (pp. 34-50). New York: Guilford Press.

Schupak-Neuberg, E., \& Nemeroff, C. (1993). Disturbances in identity and self-regulation in bulimia nervosa: Implications for a metaphorical perspective of "body as self". International Journal of Eating Disorders, 13, 335-347.

Smeets, M. (1997). The rise and fall of body size estimation research in anorexia nervosa: A review and reconceptualization. European Eating Disorders Review, 5, 75-95.
Smeets, M., Smit, F., Panhuysen, G., \& Ingleby, D. (1998). Body perception index: Benefits, pitfalls, ideas. Journal of Psychosomatic Research, 4, 457-464.

Stein, K.F. (1996). The self-schema model: A theoretical approach to the self-concept in eating disorders. Archives of Psychiatric Nursing, 10, 96-109.

Stein, K.F., \& Nyquist, L. (2001). Disturbances in the self: A source of eating disorders. Eating Disorder Review: Current Clinical Information for the Professional Treating the Eating Disorders, May/June, 12(1), 1-4.

Stein, K.F., \& Nyquist, L. (1998, April). Self-concept deviations in women with an eating disorder. Poster presented at the 8th International Congress on Eating Disorders, New York, NY.

Steiner-Adair, C. (1990). The body politic: Normal female adolescent development and the development of eating disorders. In. C. Gilligan (Ed.), Making connections: The relational worlds of adolescent girls at Emma Willard School (pp. 162-182). Cambridge, MA: Harvard University Press.

Stice, E., Mazotti, L., Krebs, M., \& Martin, S. (1998). Predictors of adolescent dieting behaviors: A longitudinal study. Psychology of Addictive Behaviors, 12, 195-205.

Stice, E., \& Shaw, H. (1994). Adverse effects of the media portrayed thin-ideal on women and the linkages to bulimic symptomatology. Journal of Social and Clinical Psychology, 13, 288-308.

Straumann, Vookle, Berenstein, Chaiken \& Higgins. (1991). Self-discrepancies and vulnerability to body dissatisfaction and disordered eating. Journal of Personality and Social Psychology, 61, 946-956.

Strober, M. (1991). Disorders of the self in anorexia nervosa: An organismic-developmental paradigm. In C. Johnson (Ed.), Psychodynamic treatment of anorexia nervosa and bulimia nervosa (pp. 354-373). New York: Guilford Press.

Strober, M., Freeman, R., Lampert, C., Diamond, J. \& Kaye, W. (2000). Controlled family study of anorexia nervosa and bulimia nervosa: Evidence of shared liability and transmission of partial syndromes. American Journal of Psychiatry, 157, 393-401.

Thoits, P. (1986). Multiple identities: Examining gender and marital status differences in distress. American Sociological Review, 51, 259-272.

Vitousek, K.B., \& Ewald, L.S., (1993). Self-representation in eating disorders: A cognitive perspective. In Z. Segal \& S. Blatt (Eds.), The self in emotional disorders: Cognitive and psychodynamic perspectives (pp. 221-257). New York: Guilford Press.

Walsh, B.T., \& Garner, D. (1997). Diagnostic issues. In D. Garner \& P. Garfinkel (Eds), Handbook of treatment for eating disorders (2nd Ed.) (pp. 25-33). New York: Guilford Press.

Zajonc, R. (1960). The process of cognitive tuning in communication. Journal of Abnormal and Social Psychology, 51, 159-167. 